\title{
Cost-effectiveness of Prostate Cancer Screening: A Simulation Study Based on ERSPC Data
}

\author{
E. A. M. Heijnsdijk, T. M. de Carvalho, A. Auvinen, M. Zappa, \\ V. Nelen, M. Kwiatkowski, A. Villers, A. Páez, S. M. Moss, \\ T. L. J. Tammela, F. Recker, L. Denis, S.V. Carlsson, E. M. Wever, \\ C. H. Bangma, F. H. Schröder, M. J. Roobol, J. Hugosson, H. J. de Koning
}

Affiliations of authors: Department of Public Health (EAMH, TMdC, EMW, HJdK) and Department of Urology (CHB, FHS, MJR), Erasmus Medical Center, Rotterdam, the Netherlands; Tampere School of Health Sciences, University of Tampere, Tampere, Finland (AA); Unit of Epidemiology, Institute for Cancer Prevention, Florence, Italy (MZ); Provinciaal Instituut voor Hygiëne, Antwerp, Belgium (VN, LD); Department of Urology, Kantonsspital Aarau, Aarau, Switzerland (MK, FR); Department of Urology, Centre Hospitalier Regional Universitaire, Lille, France (AV); Department of Urology, Hospital de Fuenlabrada, Madrid, Spain (AP); Centre for Cancer Prevention, Queen Mary University of London, UK (SMM); Department of Urology, Tampere University Hospital and University of Tampere, Tampere, Finland (TLJT); Oncology Center, Antwerp, Belgium (LD); Department of Urology, Sahlgrenska University Hospital, Gothenburg, Sweden (SVC, JH); Memorial Sloan-Kettering Cancer Center, Department of Surgery (Urology), New York, NY (SVC).

Correspondence to: Eveline Heijnsdijk, PhD, Department of Public Health, Erasmus MC, PO Box 2040, 3000 CA Rotterdam, The Netherlands (e-mail: e.heijnsdijk@erasmusmc.nl).

\begin{abstract}
Background: The results of the European Randomized Study of Screening for Prostate Cancer (ERSPC) trial showed a statistically significant $29 \%$ prostate cancer mortality reduction for the men screened in the intervention arm and a $23 \%$ negative impact on the life-years gained because of quality of life. However, alternative prostate-specific antigen (PSA) screening strategies for the population may exist, optimizing the effects on mortality reduction, quality of life, overdiagnosis, and costs.

Methods: Based on data of the ERSPC trial, we predicted the numbers of prostate cancers diagnosed, prostate cancer deaths averted, life-years and quality-adjusted life-years (QALY) gained, and cost-effectiveness of 68 screening strategies starting at age 55 years, with a PSA threshold of 3, using microsimulation modeling. The screening strategies varied by age to stop screening and screening interval (one to 14 years or once in a lifetime screens), and therefore number of tests.

Results: Screening at short intervals of three years or less was more cost-effective than using longer intervals. Screening at ages 55 to 59 years with two-year intervals had an incremental cost-effectiveness ratio of \$73000 per QALY gained and was considered optimal. With this strategy, lifetime prostate cancer mortality reduction was predicted as $13 \%$, and $33 \%$ of the screen-detected cancers were overdiagnosed. When better quality of life for the post-treatment period could be achieved, an older age of 65 to 72 years for ending screening was obtained.
\end{abstract}

Conclusion: Prostate cancer screening can be cost-effective when it is limited to two or three screens between ages 55 to 59 years. Screening above age 63 years is less cost-effective because of loss of QALYs because of overdiagnosis. 
The European Randomized study of Screening for Prostate Cancer (ERSPC) has shown a disease-specific mortality reduction of prostate-specific antigen (PSA) screening for prostate cancer (1). After eleven years of follow-up, prostate cancer mortality was reduced by $29 \%$ after adjustment for noncompliance. In terms of absolute effect, 37 cancers would need to be detected to avert one prostate cancer death (1). Some of the screendetected prostate tumors ( $23 \%$ to $42 \%$ ) might never give rise to clinical symptoms and would not lead to death from prostate cancer (2). These overdetected cancers reduce quality of life and result in higher costs because of overtreatment (3), affecting the balance of benefits and harms as well as cost-effectiveness of PSA testing for prostate cancer. In our recent study, we demonstrated that the introduction of a screening program between the ages of 55 to 70 with a four-year interval would result in a gain of 52 life-years and 41 quality-adjusted life-years (QALYs) per 1000 men over their life span (a 23\% negative impact on the life-years gained because of quality of life [4]).

Very recently the American Urological Association (AUA) recommended shared decision-making for men age 55 to 69 years who are considering PSA screening, but they gave no clear indication of the screen interval. In the ERSPC, the Swedish center used a two-year screening interval, whereas the other centers used four-year intervals (1). In the United States, annual screening is more common. There are no trials comparing different screening intervals, and such empirical studies are highly unlikely to be conducted because of the immense resources required.

Few recent cost-effectiveness studies have been published using QALYs gained. Most cost-effectiveness studies for prostate cancer screening have been performed before large screening trial results had been published and showed very inconsistent results $(5,6)$.

The aim of this study was to assess the cost-effectiveness of prostate cancer screening. Based on data of the ERSPC trial various prostate cancer screening strategies were modeled to find the optimal screening intervals and ages.

\section{Methods}

\section{The MIcrosimulation SCreening Analysis Model}

MIcrosimulation SCreening Analysis (MISCAN) was used for the evaluation of prostate cancer screening. The MISCAN prostate cancer model was developed in 2003 (7). Since then, the model has been adjusted to explicitly model the metastatic stages, treatment, survival, and cure rates $(8,9)$. MISCAN is a stochastic model that simulates individual life histories. The natural history of prostate cancer starts with a transition from "no prostate cancer" into preclinical screen-detectable prostate cancer. Tumor development is modeled as a progression through 18 stages (a combination of clinical T-stage T1, T2 and T3+, differentiation grade Gleason sum less than 7,7 and more than 7, and metastatic stage 0 or 1). In each preclinical stage, the tumor may progress into another preclinical stage, become screen detected, or clinically diagnosed (Figure 1). For each individual, the model predicts two life histories: one in the absence of screening and one in the presence of screening.

The cancers were divided into clinically diagnosed cancers, relevant screen-detected cancers, and overdetected cancers (cancers that would not have become clinically diagnosed during a person's life). The model parameters for the disease and the test sensitivity were estimated with the use of data from the Rotterdam and Göteborg ERSPC centers (46000 men, age 55-69 years) and the Dutch National Cancer Registry, and the model was validated with the use of incidence data from all ERSPC centers. Other cause mortality was modeled using Dutch life expectancy. The model and validation have been described before (4).

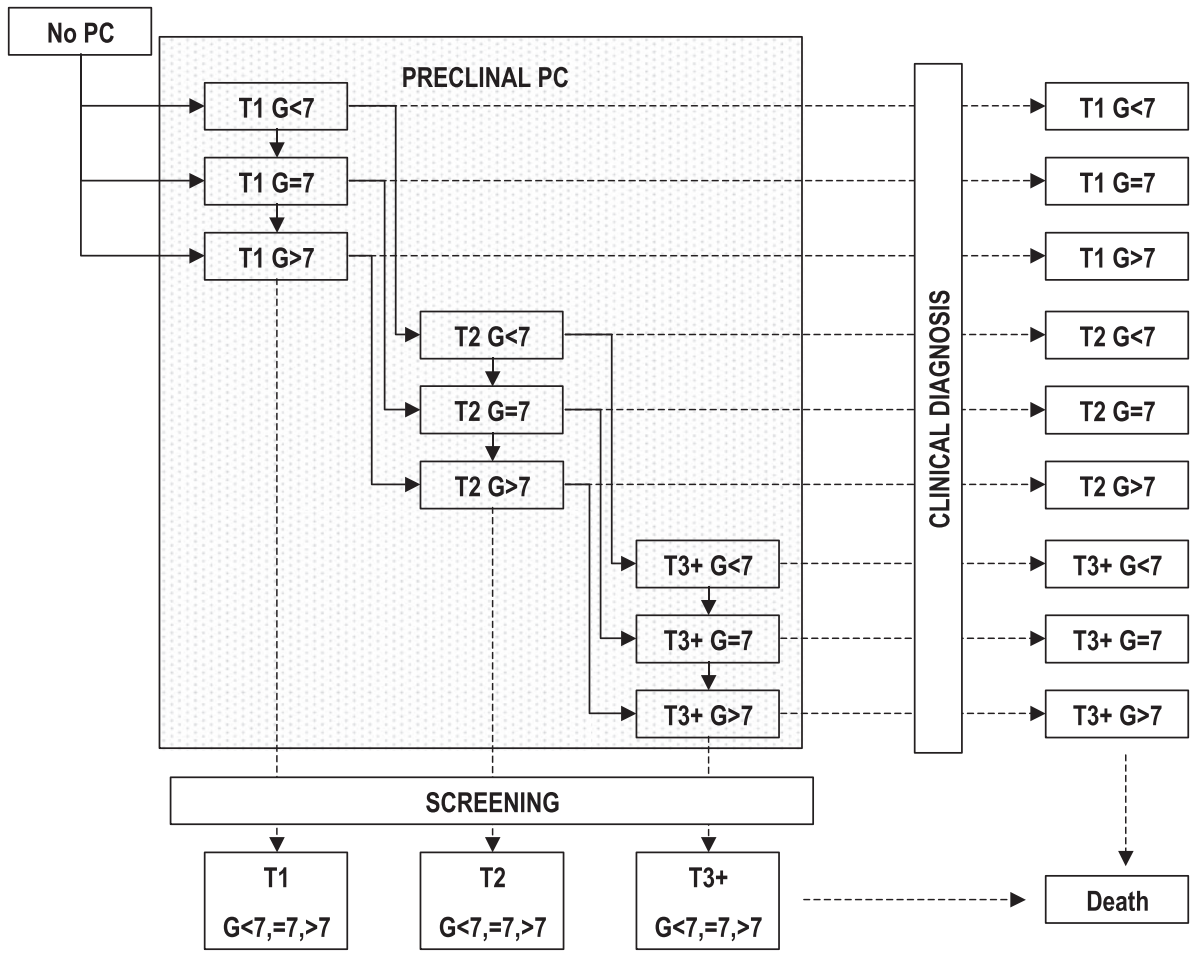

Figure 1. Prostate cancer develops from no prostate cancer via one or more screen-detectable preclinical stages to a clinically diagnosed cancer or screen-detected cancer. The arrows indicate the possible transitions. Each state can be local or metastatic, but for simplicity this is not illustrated. $\mathrm{G}=\mathrm{Gleason}$ score; $\mathrm{T}=$ tumor stage. 
The treatment assignment in MISCAN was based on age, stage, and Gleason score-specific distribution of primary treatments (radiation therapy, radical prostatectomy, and active surveillance) in the Rotterdam Center of the ERSPC. It was assumed that $30 \%$ of men under active surveillance receive a secondary treatment within seven years. All men dying of prostate cancer as well as all men with metastases received palliative treatment.

Survival without treatment was modeled by using the Gleason score-specific survival curves for men detected with locoregional prostate cancer (10). For distant disease, survival curves based on SEER data were used. The effects of treatment were modeled by assuming a relative risk of dying of 0.65 for radical prostatectomy (11) compared with watchful waiting. The same relative risk was assumed for radiation therapy.

The cure rate assumption was used to calculate the survival: A proportion of the screen-detected men with a local regional cancer will be cured, and the remaining are not cured and die of prostate cancer or other causes at exactly the same time as they would have in a situation without screening. This stagedependent cure rate was estimated for a prostate cancer mortality reduction of $29 \%$ after a follow-up of 11 years for men who attended at least one screen, corresponding to the prostate cancer mortality reduction of screened men in the ERSPC (1). This resulted in cure rates of 0.51 for Gleason less than 7, 0.30 for Gleason 7, and 0.11 for Gleason more than 7.

\section{Screening Protocols}

A cohort of 10 million men age 55 years in 2012 was simulated. Screening programs started in 2012, with $80 \%$ participation at each round. Screening intervals of 1, 2, 3, 4, 6, 8, 10, 12 , and 14 years, starting at age 55 years, were simulated, as well as a once in a lifetime screen. The age at which screening was stopped was varied between 55 and 75 years. The corresponding costs and effects were calculated until the year 2060, when all men in the cohort would have died.

\section{Costs}

The unit costs of screening, diagnoses, primary treatment, follow-up and palliative care were obtained from the literature (3). The costs were calculated in 2008 US dollars by using the purchase power parity for health (12). Indirect costs were not included. The number of screening visits, diagnoses, prostate cancer deaths, treatments and life-years were predicted by the MISCAN model. To take into account biopsies with a negative result, the total number of biopsies was calculated by using the number of screen detected cancers and a mean positive predictive value of $22.7 \%$ of a biopsy in the screen arm of the ERSPC (13) and by using the number of clinically detected cancers and the positive predictive value of $35.8 \%$ of a biopsy in the control $\operatorname{arm}(14)$.

\section{Quality of Life}

QALYs were calculated by using utility estimates, values between 0 (death or worst imaginable health) and 1 (full health) representing patient desirability of a particular health state. Utility estimates and durations of all phases in screening, diagnoses, and treatment of prostate cancer were obtained from the literature (Table 1) (4). The loss in QALYs was calculated by multiplying the loss in utility with the duration of the phase in Table 1 and the number of men in a phase obtained from MISCAN. For example, when 800 men are screened once, they lose $800 \times 0.01$ $\mathrm{x} 1 / 52$ year $=0.15$ QALYs because of the screening itself.

\section{Cost-effectiveness}

For all screening scenarios, the costs and effects (number of diagnoses, deaths prevented, treatments, life-years, and QALYs gained) were compared with a situation without screening. A discount of $3.5 \%$ was applied to both costs and effects (15). Strategies that did not have an alternative or combination of alternatives that would result in more QALYs gained at the same

Table 1. Costs, utility estimates, and durations of the various phases in screening, diagnosis, and treatment, obtained from previous studies $(3,4)$

\begin{tabular}{|c|c|c|c|c|}
\hline Intervention & Unit costs in $\$^{*}$ & Health state & Utility estimates (range) & Duration \\
\hline Screening† & $39+$ & & & \\
\hline Invitation & 3.2 & Screening attendance & $0.99(0.99-1)$ & $1 \mathrm{wk}$ \\
\hline Blood sample taking & 15.5 & & & \\
\hline PSA determination & 20.3 & & & \\
\hline Diagnosis $\uparrow$ & $277 \dagger$ & & & \\
\hline Biopsy & 150 & Diagnostic phase & $0.90(0.87-0.94)$ & $3 \mathrm{wk}$ \\
\hline PA research & 54 & Diagnosis & $0.80(0.75-0.85)$ & $1 \mathrm{mo}$ \\
\hline GP consulting & 73 & & & \\
\hline \multicolumn{5}{|c|}{ Primary therapy and follow-up $\dagger$} \\
\hline Staging & 326 & Radical prostatectomy & & \\
\hline Radical prostatectomy (RP) & 19235 & at 2 mo after procedure & $0.67(0.56-0.9)$ & $2 \mathrm{mo}$ \\
\hline Radiotherapy (RT) & 23110 & at $>2 \mathrm{mo}$ to $1 \mathrm{y}$ & $0.77(0.70-0.91)$ & $10 \mathrm{mo}$ \\
\hline Active Surveillance & 2588 & Radiation therapy & & \\
\hline 19 PSA tests $\ddagger$ & $680 \neq$ & at 2 mo after procedure & $0.73(0.71-0.91)$ & $2 \mathrm{mo}$ \\
\hline 10 DRE $\ddagger$ & $800 \neq$ & at $>2 \mathrm{mo}$ to $1 \mathrm{y}$ & $0.78(0.61-0.88)$ & $10 \mathrm{mo}$ \\
\hline 4 biopsies $\ddagger$ & $1108 \ddagger$ & Active surveillance & $0.97(0.85-1.00)$ & $\operatorname{maximal} 7 \mathrm{y}$ \\
\hline Follow-up & 245 & One year after treatment & $0.95(0.93-1.00)$ & $9 \mathrm{y}$ \\
\hline \multicolumn{5}{|l|}{ Advanced disease $†$} \\
\hline \multirow[t]{2}{*}{ Palliative therapy } & 20000 & Palliative therapy & $0.60(0.24-0.86)$ & $30 \mathrm{mo}$ \\
\hline & & Terminal illness & $0.40(0.24-0.40)$ & $6 \mathrm{mo}$ \\
\hline
\end{tabular}

* 2008 US dollars. DRE = digital rectal examination; GP = general practitioner; PA = pathological research; PSA = prostate-specific antigen.

† Costs represent the total costs of screening, diagnosis, primary therapy, and follow-up and advanced disease.

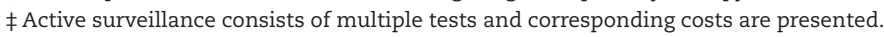


or lower net costs were identified as the efficient strategies. For every efficient strategy we determined the incremental costeffectiveness ratio (ICER), which is calculated as the incremental net costs per incremental QALY gained compared with the previous cost-efficient strategy. The strategy with an ICER value up to a threshold of $\$ 100000$ per QALY gained was considered as optimal (16).

\section{Sensitivity Analysis}

One-way sensitivity analyses were performed by varying key model parameters. For the utility estimates, the highest and lowest values were used (Table 1). A separate analysis was performed using a utility estimate of one for the postrecovery period (while retaining all the other utility estimates). The costs were varied by $20 \%$. In addition, the cost-effectiveness was calculated in the absence of overdiagnosis and for a prostate cancer mortality reduction as a result of screening of $56 \%$ after 14 years of follow-up, as has been found in the Göteborg trial (17).

\section{Results}

\section{Effects of Screening Ages and Interval}

The simulations predicted that without screening 120 per 1000 men would be diagnosed and 32 would die from prostate cancer (Table 2). A single screen at age 55 years would result in four additional cases diagnosed and one prostate cancer death prevented (5\% mortality reduction) with 18 life-years gained (17 QALYs) per 1000 men (6.6 quality adjusted days per man). The cost-effectiveness was $\$ 31467$ / QALY gained (3.5\% discounted). More intensive screening would increase the number of cancers detected, the mortality reduction, overdiagnosis, the life-years, and QALYs gained as well as the costs. The increase in total costs was mainly because of an increase in treatment costs. The largest number of life-years was gained with screening at oneyear intervals at age 55 to 75 years, but the cost-effectiveness was poor with $\$ 320042$ per QALY gained.

For each level of costs, most life-years were gained with screening at one- or two-year intervals (Figure 2A). The largest gain in QALYs was obtained by screening at one-year intervals from age 55 to 63 years (Figure 2B; an explanation of Figure $2 \mathrm{~B}$ is given in the Supplementary Materials, available online). For the single screen options, most QALYs were gained by a screen at age 57 years. The strategies on the efficiency frontier (the most effective strategies) had three-, two-, or one-year intervals. Screening between age 55 and 59 years with two-year intervals yielded an ICER closest to $\$ 100000$ per QALY gained (\$73000 per QALY gained) and was therefore regarded as optimal (Table 3). Using this strategy of only three screens, a $13 \%$ prostate cancer mortality reduction was predicted, with $33 \%$ of the screen-detected cancers overdiagnosed. Using this strategy, the annual death rate is around $25 \%$ lower between the ages 60 and 70 when compared with no screening (Figure 3).

\section{Sensitivity Analysis}

A sensitivity analysis showed that when all costs for screening, diagnosis, and treatment were increased by $20 \%$, the same strategy (age 55-59 years, two-year interval) remained closest to the optimal ICER (Table 4). Stopping screening at a later age was only favorable when the highest utility estimates were applied, when the utility estimate for the postrecovery period was one (no loss in quality of life because treatment was assumed), when no overdiagnosis would exist or when a mortality reduction of $56 \%$ was assumed. In those instances the upper age limit could be 65 to 72 years. When the lowest utility estimates were used, screening at age 55 and 57 years showed the most favorable cost-effectiveness.

Table 2. Predicted effects, costs, and cost-effectiveness for various screening scenarios per 1000 men*

\begin{tabular}{|c|c|c|c|c|c|c|}
\hline Screening scenario & No screen & $\begin{array}{l}\text { One screen at } \\
\text { age } 55 \mathrm{y}\end{array}$ & $\begin{array}{l}\text { Screening at age } \\
55-59 \text { y at } 2-y \\
\text { intervals }\end{array}$ & $\begin{array}{c}\text { Screening at age } \\
55-67 \text { y at } 4-y \\
\text { intervals }\end{array}$ & $\begin{array}{l}\text { Screening at age } \\
55-69 \text { y at } 2-y \\
\text { intervals }\end{array}$ & $\begin{array}{c}\text { Screening at age } \\
55-75 \mathrm{y} \text { at } 1-\mathrm{y} \\
\text { intervals }\end{array}$ \\
\hline Screening tests & - & 800 & 2342 & 2944 & 5706 & 13610 \\
\hline Men screened at least once & - & 800 & 935 & 955 & 989 & 997 \\
\hline \multicolumn{7}{|l|}{ Effects } \\
\hline Cancers diagnosed & 120 & 124 & 132 & 156 & 169 & 207 \\
\hline Screen-detected cancers & - & 12 & 34 & 86 & 115 & 180 \\
\hline $\begin{array}{l}\text { Overdiagnosed cancers } \\
\text { (as \% of screen-detected men) }\end{array}$ & - & $4(30)$ & $11(32)$ & $35(41)$ & $49(43)$ & $87(48)$ \\
\hline $\begin{array}{l}\text { Prostate cancer deaths } \\
\text { (\% reduction) }\end{array}$ & 32 & $31(5)$ & $28(13)$ & $25(24)$ & $23(30)$ & $20(40)$ \\
\hline Life-years gained & - & 18 & 41 & 66 & 83 & 102 \\
\hline QALYs gained & - & 17 & 36 & 50 & 61 & 64 \\
\hline \multicolumn{7}{|l|}{ Costs $\mathrm{x} \$ 1000$} \\
\hline Screening & - & 32 & 94 & 118 & 228 & 542 \\
\hline Diagnosis and treatment & 1882 & 2003 & 2229 & 2842 & 3161 & 3909 \\
\hline Palliative care & 649 & 616 & 568 & 496 & 452 & 390 \\
\hline Total costs & 2531 & 2652 & 2890 & 3456 & 3841 & 4842 \\
\hline \multicolumn{7}{|l|}{ Cost-effectiveness $\dagger$} \\
\hline $\begin{array}{l}\text { Net costs per QALY gained } \\
\text { (3.5\% discounted) }\end{array}$ & - & 31467 & 45615 & 92031 & 120185 & 320042 \\
\hline
\end{tabular}

* Effects and costs are shown without discount. The cost-effectiveness is calculated at $3.5 \%$ discount rate for effects as well as costs. In 2008 US dollars. QALY $=$ quality adjusted life year.

† The costs and effects are compared with the "no screen" situation; numbers are rounded. 
$\mathbf{A}$

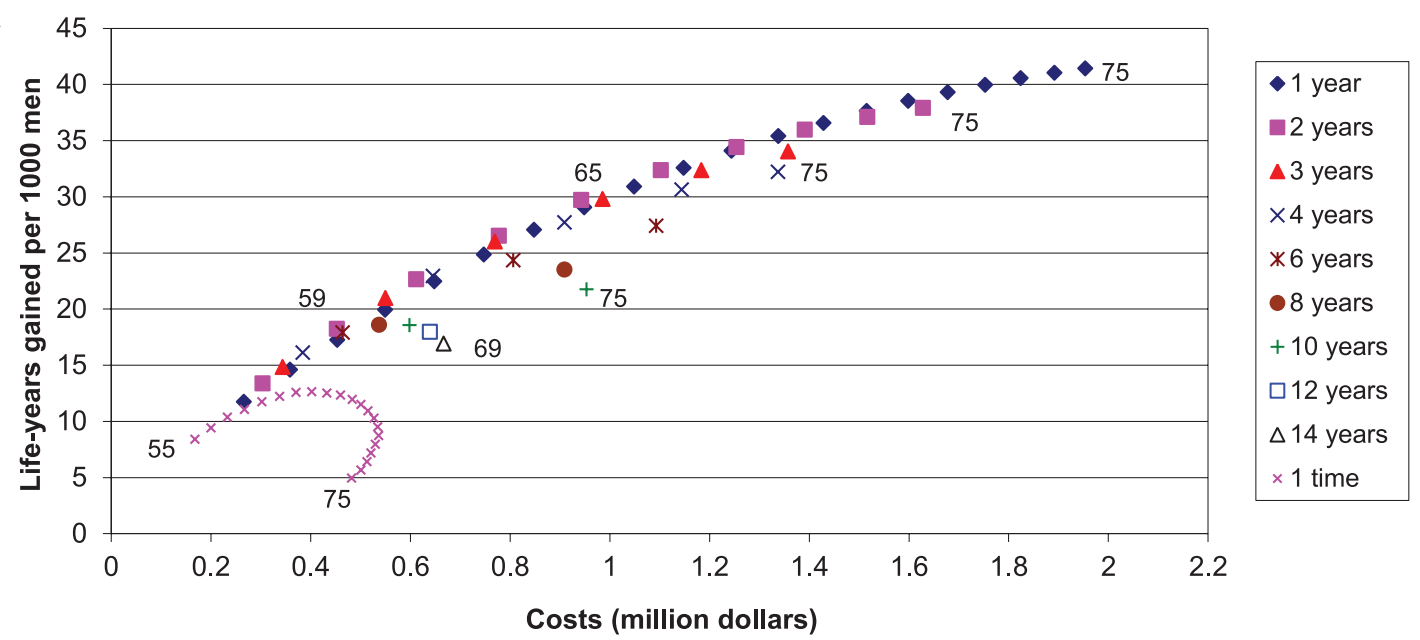

B

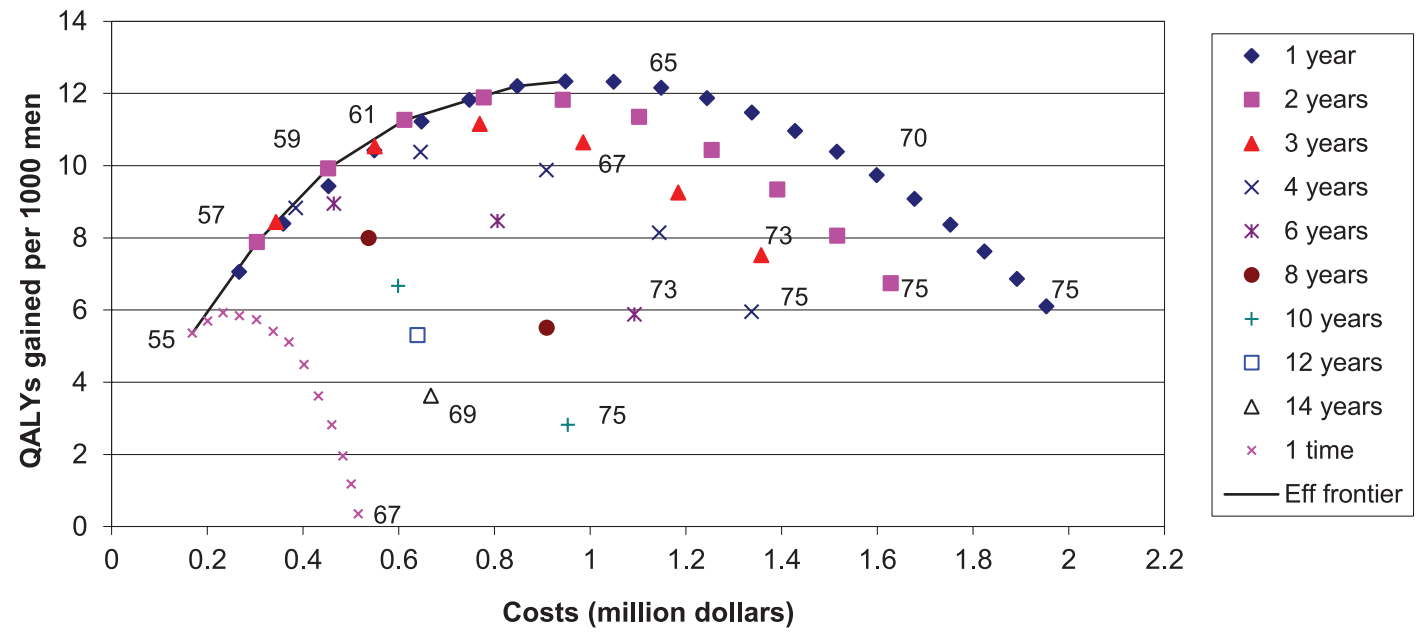

Figure 2. Net costs and (A) life-years gained or (B) quality-adjusted life-years gained (all 3.5\% discounted) per 1000 men, of PSA screening strategies varying by interval and end age. The screens start at age 55 years, except for the once in a lifetime screens. At some points in the figure, the end ages are indicated. The efficient strategies in Figure 2B are connected by the efficient frontier (Eff frontier, solid curve) and are presented in Table 3. Strategies below this line are less cost-effective. Costs are in 2008 US dollars. QALY = quality-adjusted life-year.

\section{Discussion}

Our results suggest that screening strategies with short screening intervals of at most three years are more cost-effective than those using longer intervals. Scenarios involving more frequent screening over a limited age range resulted in increased lifeyears gained, without a substantial increase in the proportion of overdiagnosed cases.

The most favorable results were obtained for screening cessation below age 60 years. The incremental cost-effectiveness ratios of these strategies were $\$ 31467$ to $\$ 72971$ per QALY gained, close to the commonly used $\$ 50000$ and $\$ 100000$ thresholds (16).

Earlier we found that men age 55 to 59 years with moderaterisk prostate cancer are also the best candidates for immediate curative treatment at the time of screen-detection, because they have the most favorable ratio between lead time and life-years gained (18).

Previous studies concerning the costs or cost-effectiveness of prostate cancer screening did not evaluate life-years gained or QALYs gained (19-24) or were based on assumptions of mortality reduction because of screening and did not use results of a prostate cancer screening trial to calibrate the model (25-31).
These studies showed large variation in cost-effectiveness from $\$ 68$ per QALY gained (29) to $\$ 729000$ per life-year saved (30), but the results are difficult to compare because of different assumptions in demographics and background risks, screening protocols, costs, effects of treatment, and screening on mortality and discount rates. Two studies have used the results of the ERSPC trial to assess cost-effectiveness of screening $(6,32)$. They found that screening is not cost-effective, with \$291817 / QALY or $\$ 262758$ per life year gained. Screening can be cost-effective when it is limited to men with five times the average risk (6), or when the number needed to treat is less than 18 (32).

Most studies have shown that screening is less cost-effective at higher ages (5). Our study suggests a lower age at cessation of screening of 59 to 61 years, whereas previous studies suggest stopping screening at age 70 to 71 years $(23,26,28,31)$. Our results can change with longer follow-up of the ERSPC trial, as a study in Göteborg suggested that nine years after termination of screening the prostate cancer mortality in the screen arm caught up (33). However, the ERSPC now has two additional years of follow-up, which confirms the relatively stable mortality reduction, compared with the nine and 11 years follow-up (34). The current model can also replicate the mortality reduction after 13 years. 


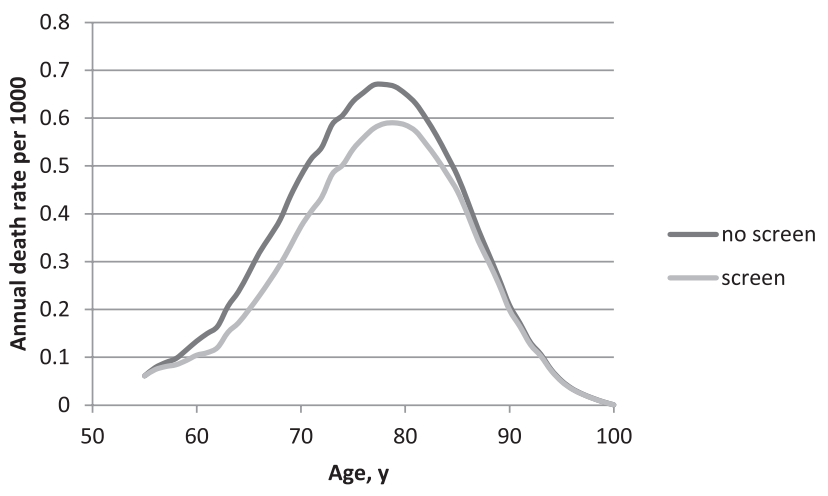

Figure 3. The annual death rate per 1000 men by age in the absence of screening as well as in the presence of screening from age 55 to 59 years with two-year intervals.

Our conclusion on short intervals may seem surprising. Apparently much of the overdiagnosis is already covered by four-year interval screening, whereas a shorter interval can still increase the prostate cancer mortality reduction.

Strong points of our study are that the model incorporates a mortality reduction as a result of screening based on a large prostate screening trial and that by simulating a cohort of men for their lifetimes, all costs and effects can be taken into account. However, our approach also has some limitations. Since the model is based on the ERSPC trial, in which the majority of men were screened from age 55 years, the model is not validated to predict results for starting screening before age 55 years. Several modeling studies have suggested that starting screening at age 40 years may improve the cost-effectiveness, or at least lead to comparable prostate cancer mortality reductions with fewer harms $(20,22,28)$. Also, varying PSA thresholds for biopsy referral for different subgroups can improve harm-benefit tradeoff (20). For example, higher PSA thresholds can be used for older ages, the screening interval may be based on baseline PSA level, comorbidity can be taken into account, or other risk stratification methods can be used. We assumed a fixed effect of screening for the entire population. However, this effect can depend on factors such as family history, comorbidity, and ethnicity.

Another limitation of the present study is that most of the disease-specific and treatment parameters in the model were based on the data of the ERSPC Rotterdam and the Dutch Cancer Registry, and might not be directly applicable to other populations, especially already more intensively screened populations. Also, the treatment modalities and effects can change in the future. If active surveillance will be used more frequently, the total treatment costs will be lower, whereas an increase in radical prostatectomy or radiotherapy would increase the total costs.

We have not included out-of-pocket costs and indirect costs, such as administrative costs, loss of productivity and income, traveling costs, and time and financial losses by family members. Therefore, it is expected that the actual total costs of screening will be higher than predicted in this study. Also, in this study cost prices are used, whereas reimbursement rates can be higher. Using higher costs would probably not substantially alter the ranking of the results.

The sensitivity analysis showed large differences in costeffectiveness between the highest and lowest utility estimates. A substantial part of this variation is caused by the utility estimate for the postrecovery period, because the duration of this health state (the residual life) is around 10 years for most men. 


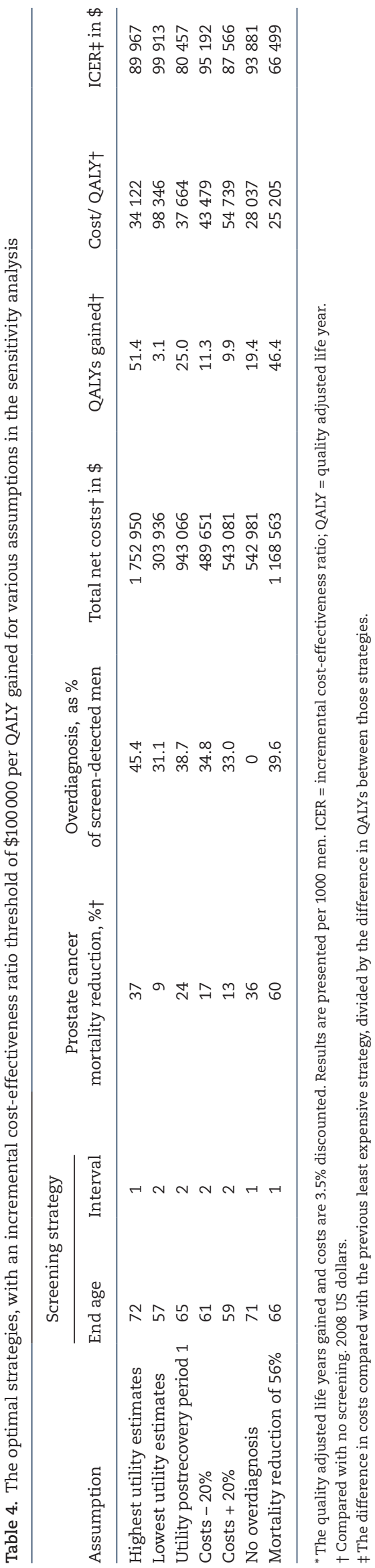

Long-term adverse effects from treatment influence the quality of life in the postrecovery period. Quality of life can also be affected more at younger ages than at older ages. However, data for the long-term quality of life after treatment are lacking. Most adverse effects affecting the urinary tract and bowel are relieved after some years, but substantial symptoms persist in many patients up to five years after treatment (35-38). In our base model, we used a utility estimate of one for the time period more than ten years after diagnosis. The use of QALYs to weigh the harms and benefits has been discussed before (4). Expressing harms and benefits in the same units has been proposed as ideal for providing the evidence base for practice guidelines (39). When only life-years gained are taken into account, the costeffectiveness is comparable with the cost-effectiveness using the highest utility estimates, and the optimal strategy would be screening from age 55 to 70 years with one-year intervals.

The American Urological Association (AUA) recommends shared decision-making for men age 55 to 69 years who are considering PSA screening and does not recommend routine PSA screening in men over age 70 years or who have less than a 10- to 15-year life expectancy (40). The AUA also recommends a routine screening interval of two years or more to be preferred over annual screening. Our analysis shows that screening over age 60 years is already less favorable at population level. When screening with two-year intervals would be stopped at age 59 years instead of 69 years, five fewer deaths will be averted, but 38 fewer men will be overdiagnosed, still leading to 36 QALYs gained per 1000 men. Although the AUA and physicians may be reluctant to not recommend screening and shared decision making at the individual level for men age 60 to 69 years, this analysis provides further evidence of the benefit of going to two-year screening intervals. Our results are more in favor of screening than the report of the US Preventative Services Task Force (USPSTF), which recommended against PSA screening (41). The USPSTF evaluation was based on a small and inconclusively proven effect of screening, by just summing all prostate cancer screening trials, including the Prostate, Lung, Colorectal, and Ovarian Cancer (PLCO) trial, and substantial and well established harms. The PLCO trial had substantial contamination in the control arm (42), negatively affecting the power of the trial, and therefore we based our study on the ERSPC trial.

In conclusion, this analysis based on the largest randomized trial on prostate cancer screening suggests that PSA-based screening can be cost-effective when it is limited to patients age 55 to 60 years with intervals of one or two years. It might be more cost-effective to screen repeatedly between age 55 and 60 years with intervals of one or two years than to use longer intervals until older ages.

\section{Funding}

This work was supported by grants from the Netherlands Organisation for Health Research and Development (ZonMW 002822820, 22000106, 50-50110-98-311), the Dutch Cancer Society (KWF 94-869, 98-1657, 2002-277, 2006-3518), Europe Against Cancer and the fifth and sixth framework program of the European Union, by grants from agencies or health authorities in the participating countries, and by unconditional grants from Beckman Coulter. The studies in each center were funded by the following local grants:

The Netherlands: the Dutch Cancer Society (KWF 94-869, 98-1657, 2002-277, 2006-3518), the Netherlands Organisation for Health Research and Development (ZonMW 002822820, 22000106, 50-50110-98-311). 
Belgium: Europe against Cancer, Flemish Ministry of Welfare, Public Health and Family, Province and City of Antwerp, Public Centre for Social Welfare Antwerp.

Sweden: Abbott Pharmaceuticals, Sweden, Af Jochnick's Foundation, Catarina and Sven Hagstroms Family Foundation, Gunvor and Ivan Svensson's Foundation, Johanniterorden, King Gustav V Jubilée Clinic Cancer Research Foundation, Sahlgrenska University Hospital, Schering Plough, Sweden, Swedish Cancer Society, Wallac Oy, Turku, Finland.

Finland: the Academy of Finland (grants \#123054 and \#260931), the Cancer Society of Finland, the Competitive Research Funding of the Pirkanmaa Hospital District, Perkin Elmer-Wallac.

Italy: Italian League for the Fight aganist Cancer (LILT Lega Italiana per la Lotta contro i Tumori), Italian Association for Cancer Research (AIRC Associazione Italiana Ricerca sul Cancro), National Research Council (CNR Consiglio Nazionale delle Ricerche Tuscany), Region (Regione Toscana).

Spain: partially supported by the Spanish Fondo de Investigación Sanitaria (FIS) grants 96/0248, 99/0245, 02/0732, and $06 / 0831$.

Switzerland: the Horten Foundation, Aargau Cancer League, Swiss Cancer League (Grant Nr KFS 787-2-1999 and 01112-022001), Health Department of Canton Aargau, Prostate Cancer Research Foundation, Baugarten Foundation, and the Messerli Foundation.

International coordination: European Union Grants SOC 95 35109, SOC 96201869 05F022, SOC 97 201329, SOC 98 32241, the 6th Framework Program of the EU: PMark: LSHC-CT-2004-503011.

Unconditional grants: Beckman-Coulter-Hybritech, Inc.

\section{Notes}

The study sponsors had no role in the design of the study, the collection, analysis, or interpretation of the data, the writing of the manuscript, nor the decision to submit the manuscript for publication.

This publication was partially made possible by Grant Number U01CA157224 01 from the National Cancer Institute as part of the Cancer Intervention and Surveillance Modeling Network (CISNET), which supported underlying development of the simulation model used. Its contents are solely the responsibility of the authors and do not necessarily represent the official views of the National Cancer Institute.

\section{References}

1. Schröder FH, Hugosson J, Roobol MJ, et al. Prostatecancer mortality at 11 years of follow-up. N Engl J Med. 2012;366(11):981-990.

2. Draisma G, Etzioni R, Tsodikov A, et al. Lead time and overdiagnosis in prostate-specific antigen screening: importance of methods and context. J Natl Cancer Inst 2009;101(6):374-83.

3. Heijnsdijk EA, der Kinderen A, Wever EM, et al. Overdetection, overtreatment and costs in prostate-specific antigen screening for prostate cancer. Br J Cancer 2009;101(11):1833-8.

4. Heijnsdijk EA, Wever EM, Auvinen A, et al. Quality-of-life effects of prostate-specific antigen screening. N Engl J Med 2012;367(7):595-605.

5. Garg V, Gu NY, Borrego ME, et al. A literature review of costeffectiveness analyses of prostate-specific antigen test in prostate cancer screening. Expert Reu Pharmacoecon Outcomes Res 2013;13(3):327-42.

6. Martin AJ, Lord SJ, Verry HE, et al. Risk assessment to guide prostate cancer screening decisions: a cost-effectiveness analysis. Med J Aust 2013;198(10):546-50.
7. Draisma G, Boer R, Otto SJ, et al. Lead times and overdetection because of prostate-specific antigen screening: estimates from the European Randomized Study of Screening for Prostate Cancer. J Natl Cancer Inst 2003;95(12):868-78.

8. Wever EM, Draisma G, Heijnsdijk EA, et al. How does early detection by screening affect disease progression? Modeling estimated benefits in prostate cancer screening. Med Decis Making 2011;31(4):550-8.

9. Wever EM, Hugosson J, Heijnsdijk EA, et al. To be screened or not to be screened? Modeling the consequences of PSA screening for the individual. Br J Cancer 2012;107(5):778-84.

10. Albertsen PC, Hanley JA, Fine J. 20-year outcomes following conservative management of clinically localized prostate cancer. JAMA 2005;293(17):2095-101.

11. Bill-Axelson A, Holmberg L, Filen F, et al. Radical prostatectomy versus watchful waiting in localized prostate cancer: the Scandinavian prostate cancer group-4 randomized trial. J Natl Cancer Inst 2008;100(16):1144-54.

12. OECD Health Data, Organisation for Economic Co-operation and Development, Pars, France. (Accessed June 5, 2013 at http://www.oecd.org/els/health-systems/OECDHealthData2012FrequentlyRequestedData_Updated_October. xls\#'Public).

13. Postma R, Schröder FH, van Leenders GJ, et al. Cancer detection and cancer characteristics in the European Randomized Study of Screening for Prostate Cancer (ERSPC)--Section Rotterdam. A comparison of two rounds of screening. Eur Urol 2007;52(1):89-97.

14. Otto SJ, van der Cruijsen IW, Liem MK, et al. Effective PSA contamination in the Rotterdam section of the European Randomized Study of Screening for Prostate Cancer. Int J Cancer 2003;105(3):394-9.

15. The guidelines manual January 2009. National Institute for Health and Clinical Excellence, 2009. (Accessed April 28, 2009, at http://www.nice.org.uk/aboutnice/howwework/developingniceclinicalguidelines/clinicalguidelinedevelopmentmethods/GuidelinesManual2009.jsp.).

16. The Cost-Effectiveness Analysis Registry, Center for the Evaluation of Value and Risk in Health. Boston, ICRHPS, Tufts Medical Center. (Accessed June 5, 2013 at http://www.cearegistry.org).

17. Hugosson J, Carlsson S, Aus G, et al. Mortality results from the Goteborg randomised population-based prostate-cancer screening trial. Lancet Oncol 2010;11(8):725-732.

18. Wever EM, Heijnsdijk EA, Draisma G, et al. Treatment of localregional prostate cancer detected by PSA screening: benefits and harms according to prognostic factors. $\mathrm{Br} \mathrm{J}$ Cancer 2013;108(10):1971-7.

19. Bermudez-Tamayo C, Martin Martin JJ, Gonzalez Mdel P, et al. Cost-effectiveness of percent free PSA for prostate cancer detection in men with a total PSA of $4-10 \mathrm{ng} / \mathrm{ml}$. Urol Int 2007;79(4):336-44.

20. Gulati R, Gore JL, Etzioni R. Comparative effectiveness of alternative PSA-based prostate cancer screening strategies. Ann Intern Med 2012;in press.

21. Perez-Niddam K, Thoral F, Charvet-Protat S. Economic evaluation of a prostate cancer screening program in France: a decision model. Crit Rev Oncol Hematol 1999;32(2):167-73.

22. Ross KS, Carter HB, Pearson JD, et al. Comparative efficiency of prostate-specific antigen screening strategies for prostate cancer detection. JAMA 2000;284(11):1399-405.

23. Ross KS, Guess HA, Carter HB. Estimation of treatment benefits when PSA screening for prostate cancer is discontinued at different ages. Urology 2005;66(5):1038-42.

24. Sennfält K, Sandblom G, Carlsson P, et al. Costs and effects of prostate cancer screening in Sweden--a 15-year follow-up of a randomized trial. Scand J Urol Nephrol 2004;38(4):291-8. 
25. Barry MJ, Fleming C, Coley CM, et al. Should Medicare provide reimbursement for prostate-specific antigen testing for early detection of prostate cancer? Part IV: Estimating the risks and benefits of an early detection program. Urology 1995;46(4):445-61.

26. Benoit RM, Gronberg H, Naslund MJ. A quantitative analysis of the costs and benefits of prostate cancer screening. Prostate Cancer Prostatic Dis 2001;4(3):138-45.

27. Coley CM, Barry MJ, Fleming C, et al. Early detection of prostate cancer. Part II: Estimating the risks, benefits, and costs. American College of Physicians. Ann Intern Med 1997;126(6):468-79.

28. Howard DH. Life expectancy and the value of early detection. $J$ Health Econ 2005;24(5):891-906.

29. Kobayashi T, Goto R, Ito K, et al. Prostate cancer screening strategies with re-screening interval determined by individual baseline prostate-specific antigen values are cost-effective. Eur J Surg Oncol 2007;33(6):783-9.

30. Krahn MD, Mahoney JE, Eckman MH, et al. Screening for prostate cancer. A decision analytic view. JAMA 1994;272(10):773-80.

31. Zhang J, Denton BT, Balasubramanian H, et al. Optimization of PSA screening policies: a comparison of the patient and societal perspectives. Med Decis Making 2012;32(2):337-49.

32. Shteynshlyuger A, Andriole GL. Cost-effectiveness of prostate specific antigen screening in the United States: extrapolating from the European study of screening for prostate cancer. $J$ Urol 2011;185(3):828-32.

33. Grenabo Bergdahl A, Holmberg E, Moss S, et al. Incidence of Prostate Cancer After Termination of Screening in a
Population-based Randomised Screening Trial. Eur Urol 2013;64(5):703-9.

34. Schröder FH, Hugosson J, Roobol MJ, et al. Screening and prostate cancer mortality: results of the European Randomised Study of Screening for Prostate Cancer (ERSPC) at 13 years of follow-up. Lancet 2014, epub ahead of press.

35. Johansson E, Steineck G, Holmberg L, et al. Long-term quality-of-life outcomes after radical prostatectomy or watchful waiting: the Scandinavian Prostate Cancer Group-4 randomised trial. Lancet Oncol 2011;12(9):891-9.

36. Sanda MG, Dunn RL, Michalski J, et al. Quality of life and satisfaction with outcome among prostate-cancer survivors. $\mathrm{N}$ Engl J Med 2008;358(12):1250-61.

37. Smith DP, King MT, Egger S, et al. Quality of life three years after diagnosis of localised prostate cancer: population based cohort study. BMJ 2009;339:b4817.

38. Booth N, Rissanen P, Tammela TL, et al. Health-Related Quality of Life in the Finnish Trial of Screening for Prostate Cancer. Eur Urol 2014;65(1):39-47.

39. Sox HC. Quality of life and guidelines for PSA screening. N Engl J Med 2012;367(7):669-71.

40. Carter HB, Albertsen PC, Barry MJ, et al. Early detection of prostate cancer: AUA guideline. J Urol 2013;13:04308-5.

41. Moyer VA. Screening for Prostate Cancer: U.S. Preventive Services Task Force Recommendation Statement. Ann Intern Med 2012;157(2):120-134.

42. Gulati R, Tsodikov A, Wever EM, et al. The impact of PLCO control arm contamination on perceived PSA screening efficacy. Cancer Causes Control 2012;23(6):827-35. 